\title{
Pollination and seedling ecology of Decalepis hamiltonii Wight \& Arn. (Periplocaceae), a commercially important, endemic and endangered species
}

\author{
A.J. Solomon Raju ${ }^{1} \&$ K. Venkata Ramana ${ }^{2}$ \\ 1,2 Department of Environmental Sciences, Andhra University, Visakhapatnam, Andhra Pradesh 530003, India \\ Email: ${ }^{1}$ ajsraju@yahoo.com
}

\begin{abstract}
Decalepis hamiltonii is a woody climber and annual bloomer. The flowers are characterized by nectariferous coralline corona, gynostegium and pollinia containing tetrads. The floral features such as greenish white corolla, mild fragrance, flat-shape for easy access to floral rewards, and ovary protection from the biting mouthparts of the pollinator make up cantharophilous pollination syndrome. Brachinus beetle is the principal pollinator. Thrips use floral buds to raise their offspring; they also effect pollination while collecting nectar; but they are important largely for self-pollination due to their short distance flying ability. The plant is a self-incompatible, obligate outcrosser and is substantiated by $2 \%$ natural fruit set, but each fruit produces numerous seeds. Fruits dehisce during the dry season and seed dispersal is by wind. Seeds germinate as soon as they fall in a favourable place, but only a small percentage establish seedlings. Over-exploitation, bottlenecks in sexual reproduction and seedling establishment may contribute to the endangered status of $D$. hamiltonii.
\end{abstract}

Keywords: Anemochory, cantharophily, Decalepis hamiltonii, seedling ecology, self-incompatibility.

Date of publication (online): 26 October 2009 Date of publication (print): 26 October 2009 ISSN 0974-7907 (online) | 0974-7893 (print)

Editor: K.R. Sasidharan

\section{Manuscript details:}

Ms \# 02168

Received 27 March 2009

Final received 19 June 2009

Finally accepted 03 October 2009

Citation: Raju, A.J.S. \& K.V. Ramana (2009). Pollination and seedling ecology of Decalepis hamiltonii Wight \& Arn. (Periplocaceae), a commercially important, endemic and endangered species. Journal of Threatened Taxa 1(10): 497-506.

Copyright: ( $)$ A.J. Solomon Raju \& K. Venkata Ramana 2009. Creative Commons Attribution 3.0 Unported License. JoTT allows unrestricted use of this article in any medium for non-profit purposes, reproduction and distribution by providing adequate credit to the authors and the source of publication.

Author Details: Dr. A.J. Solomon RAJu is currently an Associate Professor with more than 250 research papers. He is on the editorial board of several international journals. He is presently working on endemic and endangered plant species in southern Eastern Ghats forests with financial support from DST, CSIR and UGC.

K. Venkata Ramana is working as Junior Research Fellow from 2007 in a DST Research Project on endemic and endangered plant species. He has registered for PhD under Dr. Raju. He has published two research papers.

Author Contributions: AJSR conceived the concept, ideas, plan of work and did field work and prepared the paper. KVR did extensive field work and tabulated the observational and experimental work for the paper.

Acknowledgements: This study is a part of the research work of a project funded by the Department of Science and Technology, Government of India, New Delhi.
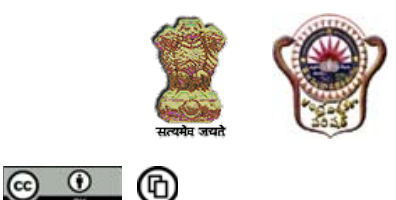

(ㅁ)

OPEN AGGESS I FREE DOWNLOAD

\section{INTRODUCTION}

The family Periplocaceae is an offshoot of the Asclepiadaceae based on certain taxonomic characteristics. Most Periplocaceae taxa inhabit tropical and subtropical forests and savannahs as woody climbers, woody shrubs, epiphytes, or herbaceous geophytes. The flower is complex and has evolved into many forms, always incorporating a coralline corona, interstaminal corona-like nectaries, and stamens fused with the stylehead into a gynostegium. Pollen is borne in tetrads which are shed after anthesis into spathulate or spoon-shaped translators that are secreted in grooves around the periphery of the style-head (Johan et al. 2001). The members of this family are entomophilous; hawkmoths and flies are recorded as legitimate pollinators; but this generalization is based on a few plant species for which information is available (Ollerton \& Liede 1997; Watson \& Dallwitz 2008).

Decalepis is a monotypic genus of Periplocaceae; it is represented by the species $D$. hamiltonii (Venter \& Verhoeven 2001). In India, it is endemic to southern India (Karnataka, Kerala, Tamil Nadu and Andhra Pradesh) and assessed as Endangered (Ravikumar \& Ved 2000; Reddy et al. 2003). It is gradually declining due to overexploitation and habitat destruction. The leaves and fruits are medicinally important. The tuberous roots (Image $5 \mathrm{~g}$ ) are used as a laxative, as an appetizer and as a health tonic. The Yanadi tribe prepares a herbal drink from the roots, and chewing the roots is regarded to give relief from indigestion. In the food industry, the root extract is used as substitute for vanillin and the roots are pickled (Vedavathy 2004; Jonathan 2006). The root extract is also used as a substitute for the roots of Hemidesmus indicus to make soft drinks and beverages. Therefore, the roots of this plant are marketed on a large scale. Regeneration of this species is severely affected since most of the plants are harvested in a reproductively immature stage. D. hamiltonii is a commercially important plant due to its importance in nutraceuticals and food products. Information on its reproduction is highly desirable so that effective strategies for domestication can be made. Hence, we report on these aspects for the first time and this information is useful for understanding its reproductive ecology and the factors responsible for the threatened status of D. hamiltonii.

\section{Materials and Methods}

D. hamiltonii is a woody climber, occurs in open rocky slopes and crevices and by stream banks, in bushes and thickets in deciduous forests of Tirumala Hills and surrounding areas of Eastern Ghats $\left(13^{\circ} 42^{\prime} \mathrm{N} \& 79^{\circ} 20^{\prime} \mathrm{E} ; 746 \mathrm{~m}\right)$. The sites for the present study include Akasaganga and Papavinasanam of Tirumala Hills in Chittoor District, Andhra Pradesh (Image 1a). This species is found to be associated with Phyllanthus polyphyllus, Syzygium alternifolium, Buchanania axillaris, Commiphora caudata, Terminalia pallida, Walsura trifolia, and Hugonia mystax. The study was conducted during 


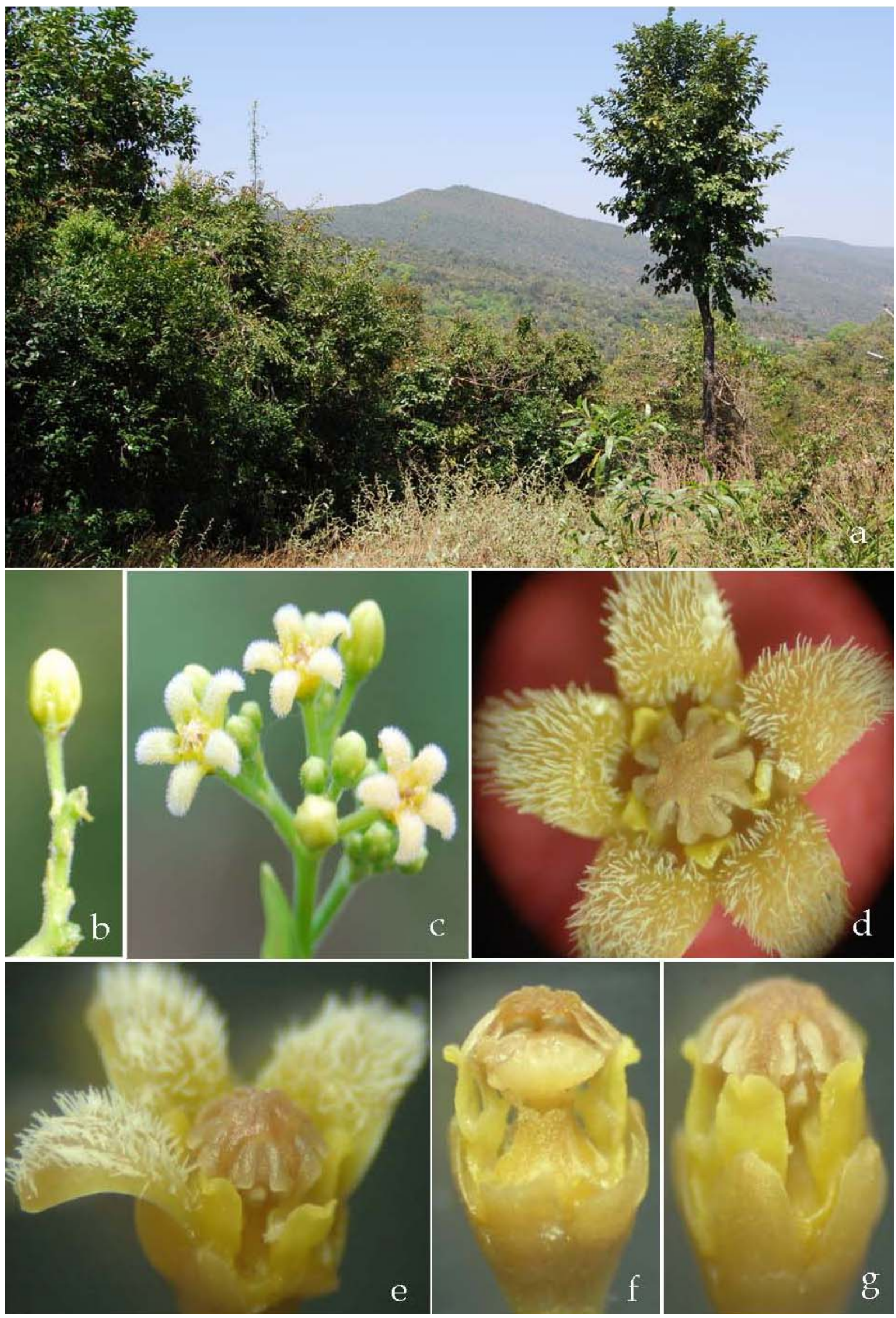

Image 1. Decalepis hamiltonii. a - Habitat; b - Mature bud; c - Buds and Flowers; d - Flower showing villous petals, coralline corona, translators alternated with stamens; e-g - Flower showing inner details of translators, stamens and stigma 


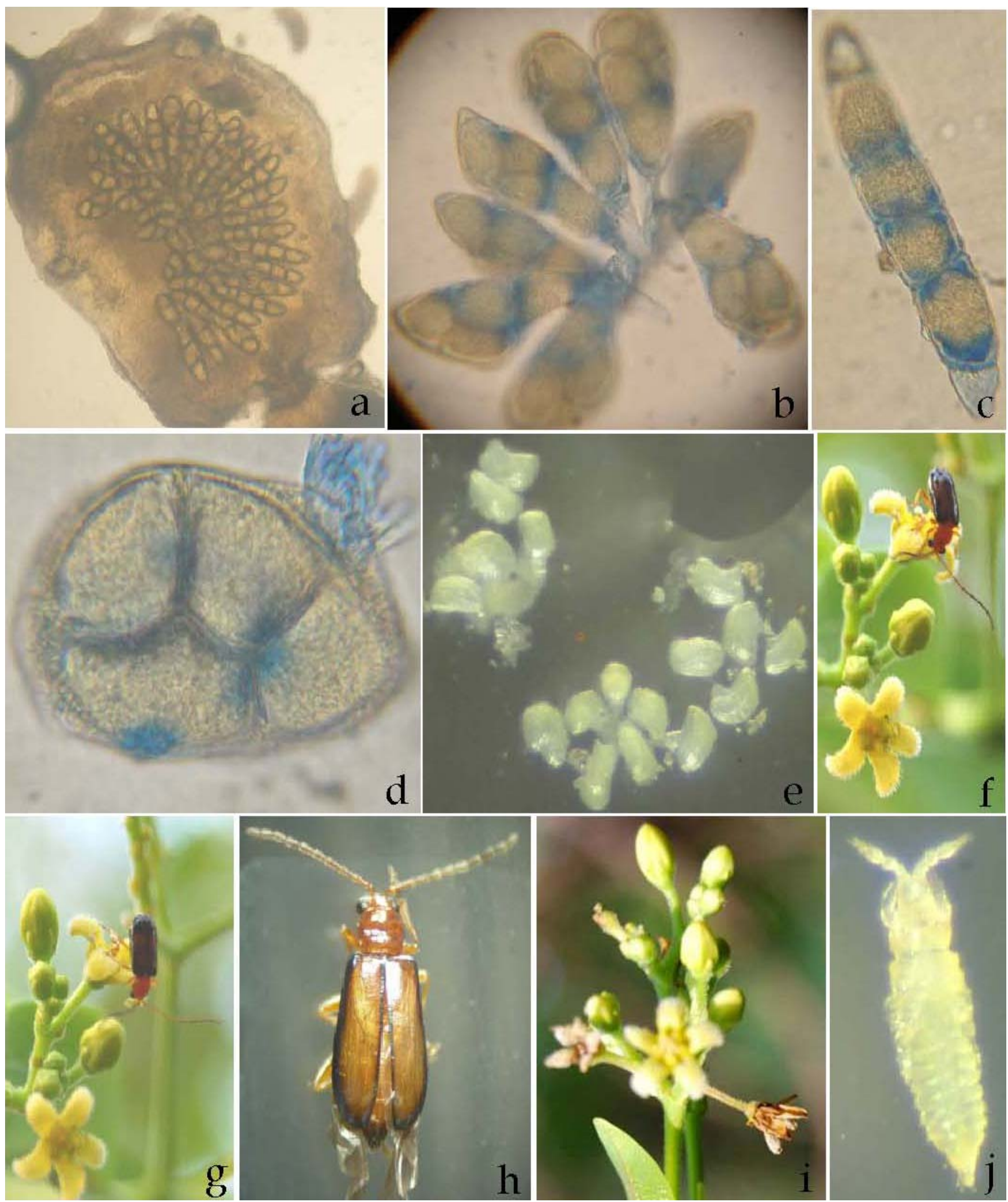

Image 2. Decalepis hamiltonii. a - Anther sac showing tetrads; b-d - Rhomboid, linear and tetrahedral tetrads; e - Ovules; f\&g - Pollen and nectar feeding by beetle; $h$ - Dorsal view of beetle; $\mathbf{i}$ - Flower damage by beetle; $\mathbf{j}$ - Thrips sp. 
2007 and 2008. The phenology and floral biology were examined following the methods of Dafni et al. (2005). Twenty five flowers were used for the study of floral morphology. Observations on flower visitors (thrips and beetles) and their foraging period with reference to pollination were recorded by using binoculars. Beetles and thrips, ten each were collected from the flowers for microscopic examination for observing the presence of pollinia and/or tetrads. Twelve inflorescences with 125 flowers were tagged and followed for quantifying flower predation rate by beetles. For autogamy, 23 inflorescences with 260 flowers were bagged and were observed for fruit set. For open-pollination fruit set, 20 inflorescences with 193 flowers were tagged. Natural fruit set rate, maturation and fruit dehiscence, dispersal, seed germination and seedlings establishment were thoroughly examined. Seed germination and seedlings establishment rate was also evaluated in experimental trays/pots; 360 seeds collected from the field were used for this purpose.

\section{Results}

In D. hamiltonii, leaf flushing occurs in May soon after monsoon showers which occur in May. This is immediately followed by flowering which extends up to August. An individual climber produces a few flowers per day (Range 1537). The flowers are borne on terminal and axillary cymose

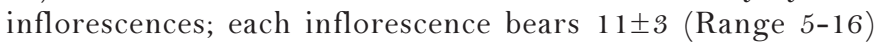
flowers which anthese over a period of 1-2 weeks. The flowers are pedicellate, small ( $5 \mathrm{~mm}$ long and $6 \mathrm{~mm}$ across), greenish white, mildly fragrant, bisexual, actinomorphic and horizontally oriented. Sepals are five, light green, $1 \mathrm{~mm}$ long and valvate. Petals are five, basally united, greenish white, villous within, $4 \mathrm{~mm}$ long and recurved. Stamens are five, fertile, filaments short and free, free from ovary, epipetalous, near the base of the corolla tube, fused with the style-head into a gynostegium.

The spoon-shaped structures called “translators' arising from the style head between the anthers conceal the stigmatic surfaces. Anthers are connivent at apex above stigma, basifixed, ovoid to rhomboid, fused to bottom of style head and dehisce by longitudinal slits. The style-head with five grooves support the anthers. Each anther contains four free pollinia. After anther dehiscence, the pollinia are deposited on the spoon of the translator. Each pollinium contains free tetrads which come in different shapes - tetrahedral, rhomboidal and linear (Image 2a-d). Single anther contains 170-230 tetrads and the total number of tetrads per flower ranges from $850-900$.

The coralline coronas are composed of five distinct padlike yellow-coloured segments, positioned on the petals in one whorl, aligned with the petals and located between the corolla and androecium. Nectariferous parts of the corona are incorporated internally into the gynostegium (Image 1d,e). Ovary has two separate carpels each contains 70-102 ovules (Image 2e), two styles which are free up to the stigma, and united terminally by the common stigma or style head. The stigma is apically flat, wet and covered above by stamens and translators (Image $1 \mathrm{f}, \mathrm{g}$ ).

Mature buds are ovoid, begin to open from 0700hr and are fully open by $0800 \mathrm{hr}$ (Image 1b,c). Anther dehiscence and stigma receptivity occur after anthesis; the stigma receptivity extends until the evening of the second day. The duration of stigma receptivity is 32 hours. Hydrogen peroxide test of Dafni et al. (2005) was followed to assess the stigma receptivity. The flowers begin to shrivel on the $3^{\text {rd }}$ day and fall off on the $4^{\text {th }}$ day. In fertilized flowers, the stamens and stigma drop off within a week while calyx, corolla and corona remain there even after fruit emergence. These floral parts fall off when the follicles begin to diverge.

Buds and flowers were found to be associated with thrips until senescence in all plants. The number of thrips found per flower varied from 8 to 10 . The thrips are $1-1.5 \mathrm{~mm}$ long, yellow (Image $2 \mathrm{j}$ ), collected nectar aliquots from nectarine corona and moved from flower to flower. The thrips were found with free tetrads but not with pollinial masses. Further, Bombardier Beetle, Brachinus sp. (Carabidae) was found visiting the flowers during daytime throughout the flowering season (Image $2 \mathrm{f}-\mathrm{h}$ ). The foraging schedule is presented in Fig. 1. The beetle is 6-9 mm long; the head and thorax are red and the abdomen is shiny metallic black. The number of beetles found per inflorescence is 1-2 at each hour during daytime. The beetle collected nectar from nectarine corona during which it was found carrying translators with anthers/pollinia. An examination of the beetles sampled from the flowers showed pollinia. It also fed on corona, petals and secretions of stigma (Image 2i) and such flowers have not produced fruits. The flower predation rate is $3 \%$. The removal of translators and anthers by the beetle exposed the stigma which facilitates to receive the tetrads in subsequent visits by the beetle.

The mature buds that were bagged to assess autogamy did not produce fruits. Natural fruit set is $2 \%$ only. Fruits begin to grow immediately after pollination and fertilization while the petals and corona are still intact (Image $3 \mathrm{a}$ ). The free ovaries

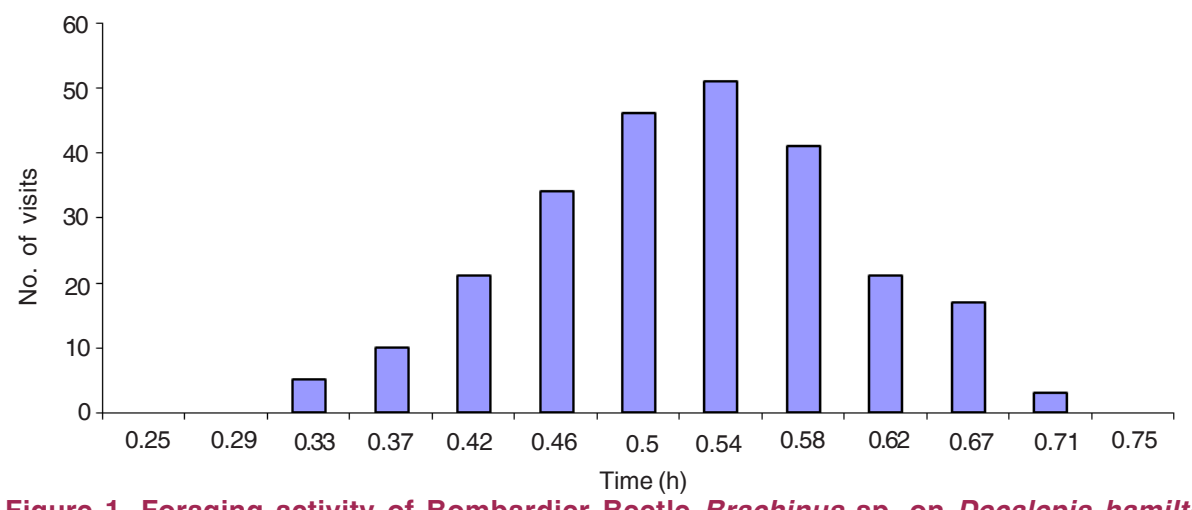

Figure 1. Foraging activity of Bombardier Beetle Brachinus sp. on Decalepis hamiltonii 


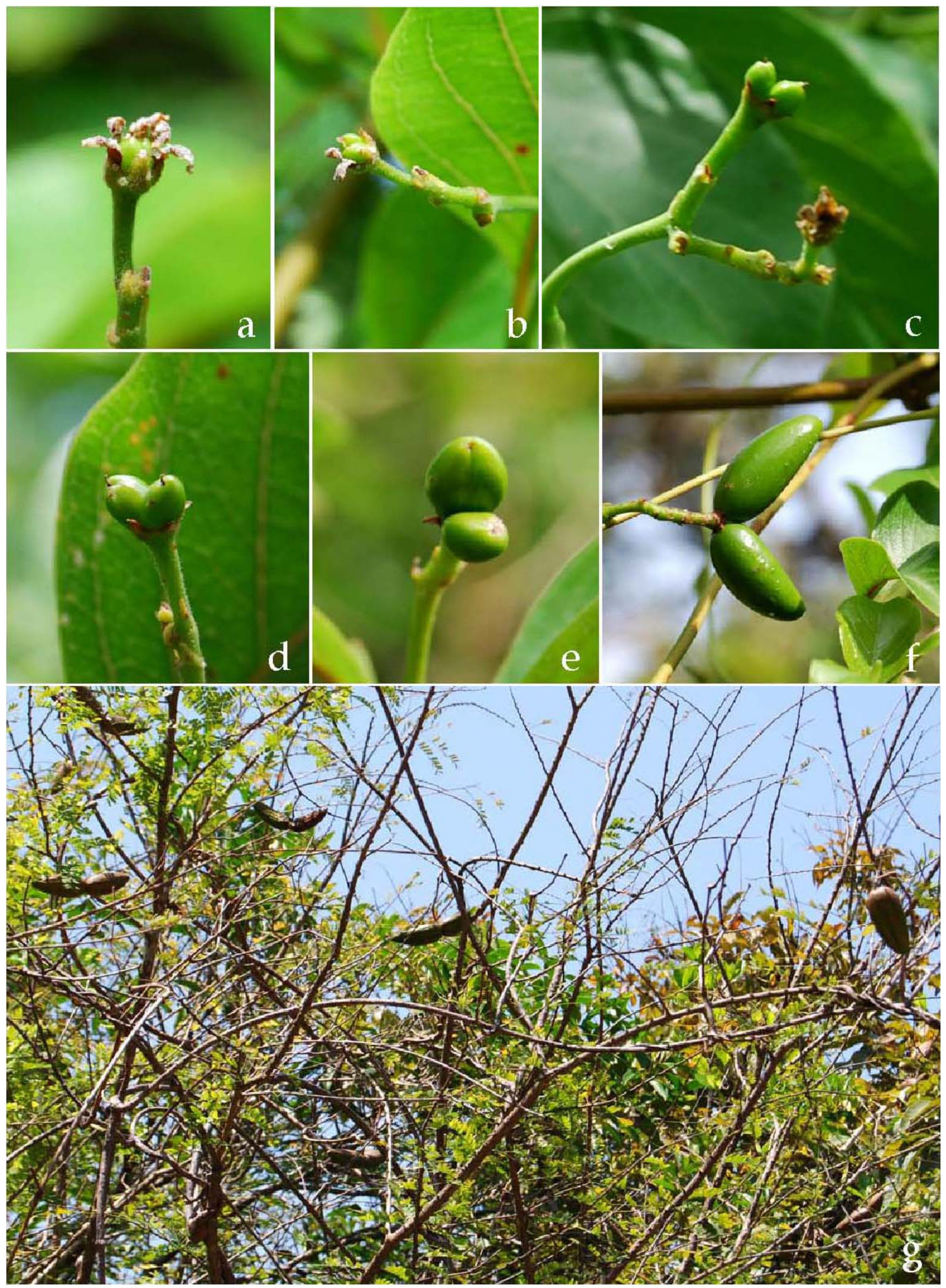

Image 3. Decalepis hamiltonii. a\&b - Developing fruit with calyx and corolla intact; c-f - Different stages of fruit development; g - Plant with ripe and dry fruits but lacking foliage 

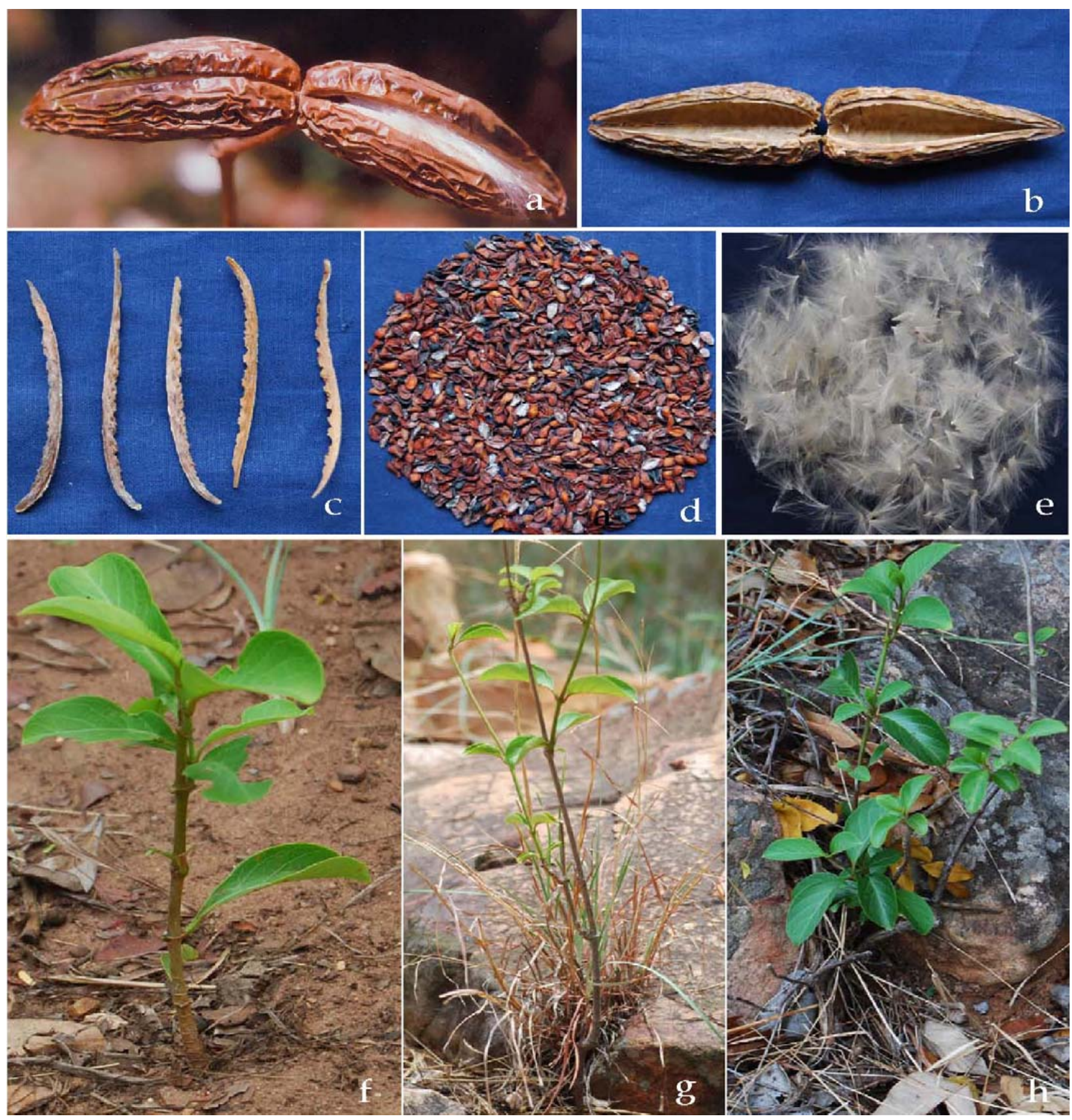

Image 4. Decalepis hamiltonii. a - 2-follicled dehisced fruit; b - Empty follicles after seed dispersal; c - Thick cylindric denticular placenta; d - Ripe and dry reddish brown seeds; e - A tuft of long silky white hairs of seed; f-h - Natural seedling establishment in litter and rocky habitats in the study area. 


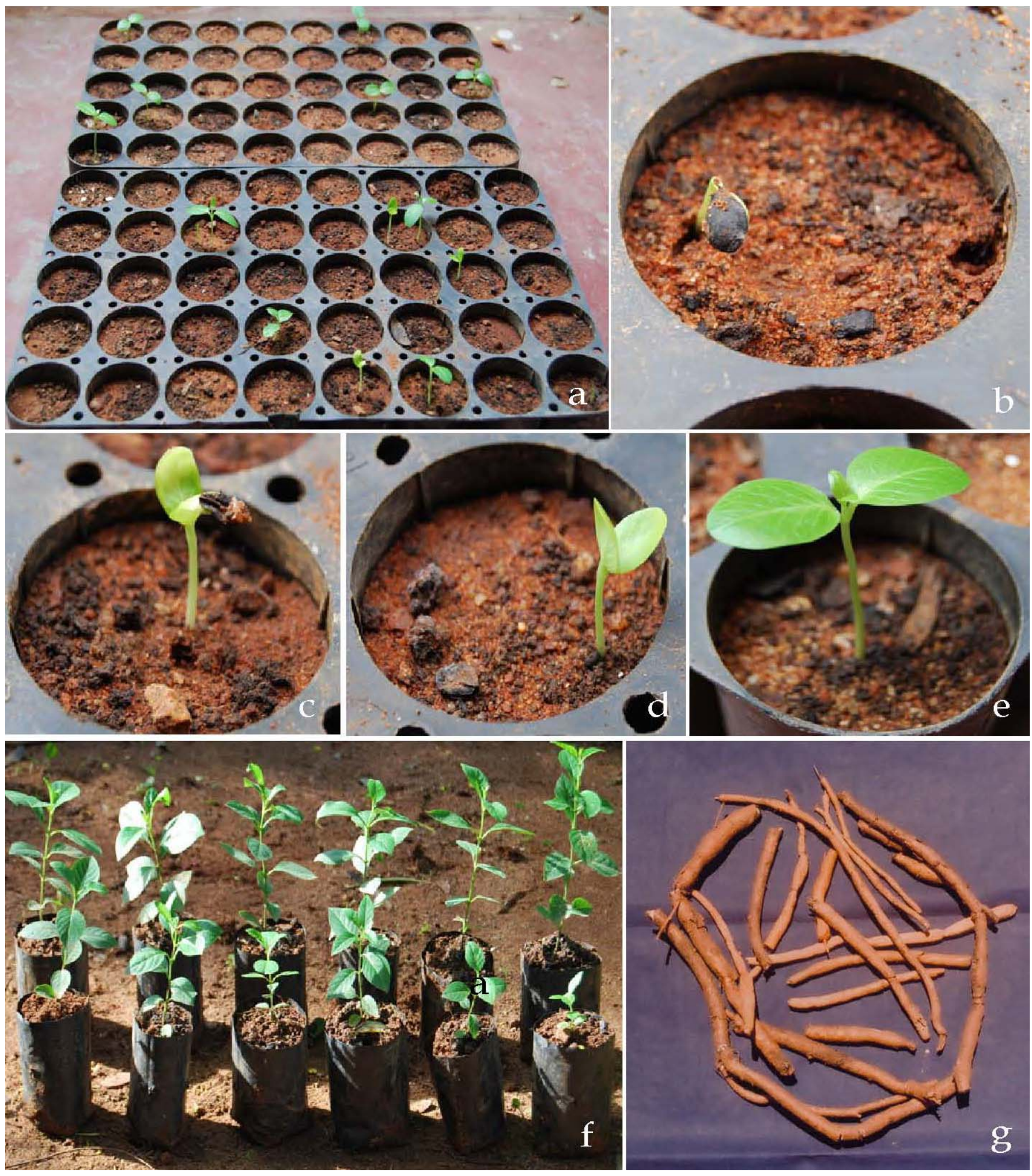

Image 5. Decalepis hamiltonii. a - Seed germination rate in experimental trays; b - Germinated seed; c-e - Different stages of seed germination; $f$ - Seedlings; $g$ - Tuberous roots 
with growing seeds begin to bulge and diverge in opposite directions from the initial stage of fruit growth and seed development and produce 2-follicled non-fleshy, dehiscent fruits (Image 3c-f). The fruits are initially green and turn dark brown when mature and ripe (Image $3 \mathrm{~g}$ ). They take 8-9 months to mature. The ripe follicles are ellipsoid, cylindrical and wrinkled; each follicle is about $60 \mathrm{~mm}$ long and $17 \mathrm{~mm}$ wide (Image 4a). The plant begins to shed leaves gradually from fruit colour transitional stage from green to brown and is leafless when fruits are ripe and dry; the period of leafless state is from January-April. Each follicle contains $70 \pm 11$, ovate, $6 \mathrm{~mm}$ long, $4 \mathrm{~mm}$ wide and $10 \mathrm{mg}$ weight reddish-brown coloured seeds crowned with a tuft of $28 \mathrm{~mm}$ long silky hairs, and are well seated on the denticles of thick cylindrical placenta of the ovary (Image 4c-e). The follicles dehisce during summer season; then the placenta with seeds intact comes out of the follicle (Image 4b). Gradually, the seeds are released from the denticles of the placenta and disseminated by wind due to their very light weight.

D. hamiltonii seeds were found to germinate soon after early monsoon showers in May on soil floor and rocky areas which are rich in litter and other organic matter (Image $4 \mathrm{f}-\mathrm{h}$ ). The experimental results of seed germination rate and thereof subsequent seedling growth and development are presented in Image 5. The results showed that seed germination rate is $13 \%$ out of which seedling establishment rate is $48 \%$ (Fig. 2). The overall seedling establishment rate in relation to total seeds sown is only 6\%. The seeds are not dormant and germination occurs from day 4 to day 45 from the date of sowing. The number of germinated seeds gradually increased, reached to a peak during $3^{\text {rd }}$ week and then onwards gradually decreased (Fig. 3).

\section{Discussion}

The flower in D. hamiltonii is characterized by nectariferous coralline corona, gynostegium, and pollinia containing tetrads; these characters are considered as evolutionary adaptations to specialized entomophily (Rahman \& Wilcock 1991; Johan et al. 2001). In Periplocaceae to which D. hamiltonii belongs, the presence of free staminal filaments and the production of free pollen tetrads which are shed after anthesis, the position of coralline corona on corolla and alignment with the corolla lobes are important distinguishing ancestral characters (Rahman \& Wilcock 1991; Fishbein 2001); all these characters are found in D. hamiltonii. Coralline corollas are typical of scales or filament-like structures in Periplocaceae, while they are of pad type in Secamonoideae and Asclepiadoideae (Kunze 1990; 1993; Nilsson et al. 1993; Klackenberg 1998). But, D. hamiltonii being a Periplocaceae member possessess coralline coronas which are typical of 'pad' type, supporting the translators marginally and present nectar at the same position.

In D. hamiltonii, lack of fruit set in bagged untreated flowers is suggestive of pre-zygotic self-incompatibility and hence the plant is an obligate outcrosser. This is further substantiated by the very small percentage of natural fruit set. Anther dehiscence during the period of stigma receptivity and deposition of tetrads from the same flower or plant on the stigma are of no use to the plant. The long period of stigma receptivity maximizes the options to receive tetrads from the flowers of conspecific plants. Thrips and beetles pick up and transfer translators with tetrads/pollinia from one flower to another while collecting nectar aliquots. The thrips are naturally shortdistance flyers and hence they largely contribute to selfpollination during their flower to flower visits on the same plant and effect cross-pollination during their flower visits to another conspecific plant; moderate winds of the study areas may extend the travel distance of thrips and accordingly they may effect more cross-pollination during their plant to plant visits. The presence of thrips in floral buds of $D$. hamiltonii indicates that egg deposition by female thrips takes place prior to bud formation and eggs hatch and produce larva or adult thrips by the time the buds open. These thrips represent suborder Terebrantia of the order Thysanoptera. The females of this group of thrips have an ovipositor with which they cut slits into plant tissue in order to insert their eggs, one egg per slit (Heming 1993). With this ability, these thrips raise their offspring in floral buds.

Ollerton \& Liede (1997) stated that pollination by Hymenoptera is most common with Lepidoptera and Diptera having a secondary, but still important role in Asclepiadaceae. Further, they mentioned that in Periplocaceae, hawkmoths and flies are legitimate pollinators and also expressed that the range of pollinators may be much broader. These two categories of insects have not been found on the flowers of D. hamiltonii. Faegri \& van der Pijl (1979) reported that the floral features such as greenish-white colour, mild fragrance and flat-topped architecture are adaptations for hawkmoth pollination. In the vicinity of $D$. hamiltonii, the diurnal hawkmoth, Macroglossum gyrans is a common visitor to Lantana camara but it never visited D. hamiltonii and hence, this study does not agree with the above report. The beetle, Brachinus sp. is the principal pollinator

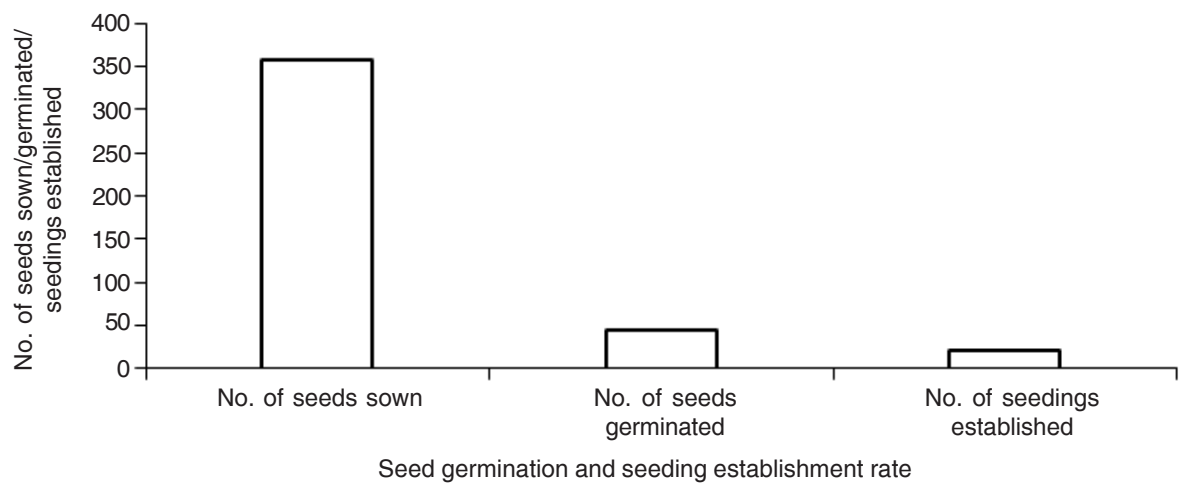

Figure 2. Seed germination and seeding establishment rate in Decalepis hamitonii 


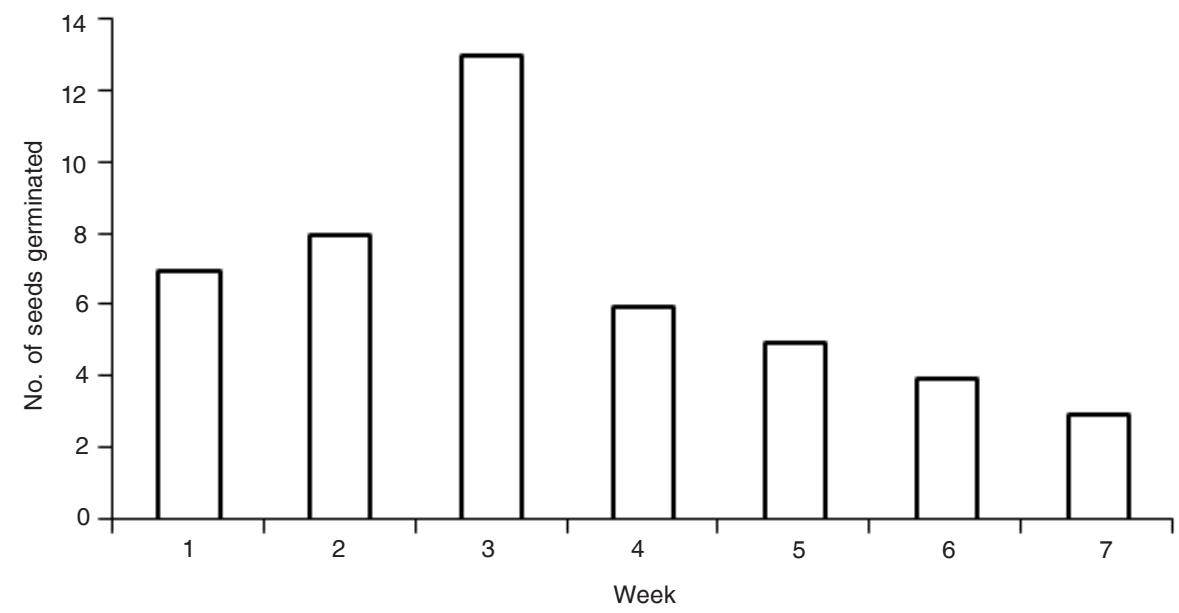

Figure 3. Seed germination rate of Decalepis hamiltonii in experimental trays/pots

of D. hamiltonii; the floral features such as greenish white colour, fragrance emission, flat-shape for easy access to floral rewards, and deep seated ovary insulated from the biting type mouthparts of the pollinating agent have been considered to be adaptive for beetle-pollination (Gullan \& Cranston 2005). The beetle feeds on nectar aliquots secreted by coralline corona. It also feeds on other floral parts causing damage to the flower; the percentage of damaged flowers is however small and hence is nearly insignificant. The flowers produced per day and per plant are few and such a small number is not sufficient to meet the forage requirement of the beetle. In effect, the beetle flies to many individual plants to collect forage and transfers tetrads to effect cross-pollination. This study adds beetles as another category of pollinators for Periplocaceae species.

The pollination mechanism in D. hamiltonii is conspicuously specialized. It involves spoon-shaped translators arising from the style head between the anthers, which conceal the stigmatic surfaces from pollinator and into each of which the pollen from the adjacent half-anther is shed. The translator adheres to the head and legs of beetle and thrips, which carry the translator and its pollen (tetrads) to other flowers of the same and/or different plants. Then, the stigma gets exposed and receives pollen from other flowers in successive visits by the pollinators (Ollerton \& Liede 1997; Watson \& Dallwitz 2008).

The natural fruit set rate in D. hamiltonii is indicative of pollinator limitation. The extended flowering pattern with the production of a small number of flowers per day and per plant is in a way appears to be the principal factor to attract only a very small number of beetles daily. However, the fruit set rate is compensated by higher number of seeds per fruit. The fruits take a long period of time to mature and dehisce to disseminate seeds. The dry season provides ideal conditions for fruit dehiscence and dispersal of seeds. The timing of fruit maturation and ripening is so perfect that it occurs during dry season when the plant is completely leafless. The light weight of the seed crowned with a tuft of silky hairs is an important aerodynamic trait characterizing "anemochory". But, anemochory is considered inefficient because it indiscriminately places propagules in every type of habitat (Greene \& Johnson 1986). In D. hamiltonii, the placenta with seeds well seated on its denticles collectively comes out of the dehisced follicle, settles on the ground and then individual seeds gradually disseminate by wind at low height. This mode of seed dispersal is more efficient than individual seed dispersal directly from the fruit.

Seeds are not dormant and germinate immediately if favourable conditions exist in soil. Experimental results also substantiate the same. A small percentage of seed germination evidenced in the experiments suggests that all seeds are not viable and this may be due defects in seed formation. Further, all those that germinated have not established seedlings; this may be due to insufficient flow of nutrients into seeds when they are being formed and to genetically inferior seeds. In the study sites also, there are a number of seedlings emerged initially but finally a few of them have established depending on the nutrient status of soil and their ability to compete with the co-emerging seedlings or plants of other species. This observation is based on 980 seedlings which have emerged naturally at the study sites; of these only 47 finally established to grow further. Therefore, the study suggests that extended flowering pattern, self-incompatibility, pollinator limitation, absence of seed dormancy, abortion of a considerable percentage of seedlings prior to establishment are contributing factors for the regulation of population size of $D$. hamiltonii in its natural areas.

The tuberous roots of $D$. hamiltonii are over-exploited prior to reproductive maturity due to their economic and medicinal values. This exploitation is the main factor for gradual decline of natural occurrence of this plant. The internal and external factors as stated above coupled with over-harvesting of roots collectively qualify $D$. hamiltonii for endemic and globally endangered status.

\section{References}

Dafni, A., P.G. Kevan \& B.C. Husband (2005). Practical Pollination Biology. Enviroquest Ltd., Canada, 590pp.

Faegri, K. \& L. Pijl, van der (1979). The Principles of Pollination Ecology. Pregamon Press, Oxford, 244pp.

Fishbein, M. (2001). Evolutionary innovation and diversification in the flowers of Asclepiadaceae. Annals of Missouri Botanical Garden 88: 603-623.

Greene, D.F. \& E.A. Johnson (1986). Dispersal capacity and seed production in anemochorous plants. Oecologia 68:629-631.

Heming, B.S. (1993). Structure, function, ontogeny, and evolution of feeding in thrips (Thysanoptera). In: C.W. Shaefer, C.W. \& R.A.B. Leschen (eds.). Functional Morphology of Insect Feeding. Thomas Say Publications in Entomology, Entomological Society of America, 
Lanham, Maryland.

Johan, H., T. Venter \& R.L. Verhoeven (2001). Diversity and relationships within the Periplocoideae (Apocynaceae). Annals of Missouri Botanical Garden 88: 550-568.

Jonathan, K.H. (2006). Ecological and economic aspects of certain endemic flora of Eastern Ghats forests. ENVIS-SDNP Newsletter Special Issue, pp.8-9.

Klackenberg, J. (1998). Taxonomy and phylogeny of the genus Camptocarpus s.l. (Periplocoideae, Asclepiadaceae). Botanische Jahrbücher fïr Systematik 120: 45-85.

Kunze, H. (1990). Morphology and evolution of the corona in Asclepiadaceae and related families. Tropen Subtropen Pflanzenwelt 76: $1-48$.

Kunze H. (1993). Evolution of the translator in Periplocaceae and Asclepiadaceae. Plant Systematics \& Evolution 185: 99-122.

Nilsson, S., M.E. Endress \& E. Grafstrom (1993). On the relationships of the Apocynaceae and Periplocaceae. Grana Supp. 2: 3-20.

Ollerton, J. \& S. Liede (1997). Pollination systems in the Asclepiadaceae: a survey and preliminary analysis. Biological Journal of Linnean Society 62: 593-610.
Rahman, M.A. \& C.C. Wilcock (1991). Diversity of life-form and distribution of the Asclepiadaceae in south-west Asia and the Indian subcontinent. Journal of Biogeography 18: 51-58.

Ravikumar, K. \& D.K. Ved (2000). Illustrated Field Guide of 100 RedListed Medicinal Plants of Conservation Concern in Souhern India. Foundation for Revitalization of Local Health Traditions (FRLHT), Bangalore, 463pp.

Reddy, C.S., K.N. Reddy, P.R.C. Prasad \& V.S. Raju (2003). Threatened Endemic Plants from Eastern Ghats, India. EPTRI-ENVIS Newsletter $9(2): 3-7$.

Vedavathy, S. (2004). Decalepis hamiltonii - An endangered source of indigenous health drink. Natural Products Radiance 3(1): 1-6.

Venter, H.J.T. \& R.L. Verhoeven (2001). Diversity and relationships within Periplocoideae. Annals of Missouri Botanical Garden 88: 550568.

Watson, L. \& M.J. Dallwitz (2008). The Families of Flowering Plants - Periplocaceae. http://delta-intkey.com/angio/www/periploc.htm.

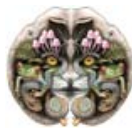

